\title{
Discussion to papers of Williams, Griffiths and Watson
}

\section{Chairman: ProfesSOR A. B. ROSSIER}

MR P. HARRIS (U.K.). We find that a percutaneous syringogram, under local anaesthesia, in the cervical or the dorsal region, using Metrizamide as the contrast, is a useful and safe investigation. What is the experience of the speakers? Could I ask about the significance of minor spinal trauma in an adult who was known to have a minor lumbo-sacral spina bifida as a baby, and who developed a steadily progressive paraparesis due to extensive syringomyelia? Concerning treatment, we have recently carried out a number of syringo-peritoneal shunt procedures, and would welcome comments on this operation.

Mr E. R. Griffiths (Australia). When should surgery be used, if at all? I agree that the surgery should be a shunt to decompress the cavity. The question is, does this arrest the condition or cause it to get better? There is very little reported experience; my series like that of Professor Rossier's is only six; in the world literature there are only I 28 cases in 40 years.

DR H. HACHEN (Switzerland). I wish to emphasise that there are important hydrodynamic changes within the cysts, and during wheelchair sport activities, and during transfers, pressures rise in the cyst, therefore we should caution our patients in the preand the early postoperative stage to refrain from excessive physical activity.

DR D. BURKE (Australia). I would value comments on a patient who presented with hiccoughs, some years following her low dorso-lumbar lesion, and no other symptoms. Examination showed evidence of spino-thalamic impairment on one side in the cervical region, ascending up to $\mathrm{C}_{4}$. We felt that the hiccoughs might have been caused by the syrinx which was proved radiologically, but hearing $\mathrm{Mr}$ Williams' slosh and suck principle, the hiccoughs may have caused the syrinx to extend. My other comment is to ask about the possible role of longitudinal traction on the cord in injury in relation to the initial mechanism of the cystic changes above and below the major lesion. I think that there has been some evidence given by a number of speakers for this mechanism; the high incidence of thoracic lesions where the cord is tethered; Watson's six out of seven lumbar lesions, where there would probably be traction on the lumbar nerve roots, the double fractures or the double lesions mentioned by one speaker, and so on. In some of the postmortem specimens, it looks as if the cord has been stretched suddenly and split along its length.

Mr B. Williams (U.K.). We have been asked why the condition of post-traumatic cyst formation in the cord is not more common; the answer is that it is vastly more common than most of us have been able to diagnose. We know that the spinal cord can have very considerable cystic cavities in it and still be quite asymptomatic. We require greater care when we follow our patients up, paying attention to what may appear to be upper limb 'arthritis' or 'neuritis', or occipital pain. We should ask about such symptoms. The major physical sign is a change in the deep reflexes in the upper limbs. Regarding Mr Harris's comment about the spina bifida case; all spina bifida patients have a type II chiari malformation, and most of them have a small cystic cavity in the cord at some stage, and if they have any kind of trauma they can get slosh affecting this cavity, and it is not uncommon for spina bifida patients to present in this way with syringomyelia. Concerning the patient presenting with hiccoughs; hiccoughs is a known feature of syringobulbia, and I feel little doubt that Dr Burke's patient had syringobulbia at the stage when he had the hiccoughs. The fact that he did not have syringobulbia later is irrelevant because these cavities can heal.

Professor A. B. Rossier (U.S.A.). Mr Williams, with regard to your comment on the transmission of pressure through the venous system, isn't it puzzling that it has been 
demonstrated in the monkey that acute obliteration of the epidural veins leads to degeneration of the cord?

MR Williams. That is an acute lesion, oedema produced by the failure of venous drainage. It is a different mechanism from that which I am referring to. Barnett is somewhat confused about this. He talks about venous back pressure. I am only pointing to the epidural veins as a means of transmitting energy. I do agree that venous stasis, venous haemorrhage and venous obstruction may be important in the early stages, but that is a different mechanism from the one with which I am principally concerned.

Professor Rossier. I have one question for all the panellists and the audience. Have you observed that the first symptom, which has often been quoted, is numbness or pain, and that it may last only a few days and then disappear, and nothing further may occur for months or even years?

DR N. Watson (U.K.). There is no doubt that pain is a prodromal symptom, and may involve an arm for 3 weeks or 3 months, before numbness is evident. We have examined patients with pain; they have loss of reflexes; they have no loss of spinothalamic function in the early stages, and the pain is prodromal. As the pain disappears so the numbness becomes evident, and in our cases who have now been followed up for over 20 years, the pain is no longer a problem. The numbness remains, and the sensory loss is always permanent, but the motor loss can improve. The reflex loss is also permanent. I feel that we are dealing with only a very small number of patients with the more severe forms of the condition; this is why I appeal for a very conservative approach to the management of the disorder.

PROFESSOR M. WeISS (Poland). You said 'conservative treatment', Dr Watson. What kind; could this be 'only observation'?

DR Watson. Yes, observation. Unless a life threatening situation arises, as in one patient who developed weakness of swallowing for a year, but this condition eventually resolved without special treatment.

DR J. WALSH (U.K.). I would make one suggestion; every new spinal injury that comes into your hands 48 or 72 hours after injury should be very carefully examined well above the lesion. You may pick up some kind of minor trauma.

DR A. G. HARDY (U.K.). I would like to remind us all that lesions can go down as well as up, and my question to all speakers would be how many have seen alteration of the sacral-lumbar segments due to cystic changes?

Dr C. E. SE IBERT (U.S.A.). In our series, three went down.

Dr B. WozIEWICZ (Poland). One.

DR Watson. Two had deterioration in the lower limbs.

Professor Rossier. I have seen one also. So it appears that the cavity can extend downwards as well as upwards. 